\title{
Healthcare access for cancer patients in the era of economic crisis. Results from the HOPE III study
}

\author{
Kyriakos Souliotis*, Eirini Agapidaki, Manto Papageorgiou \\ University of Peloponnese Corinth, GREECE
}

Received 22 October 2015; December 14 January 2015

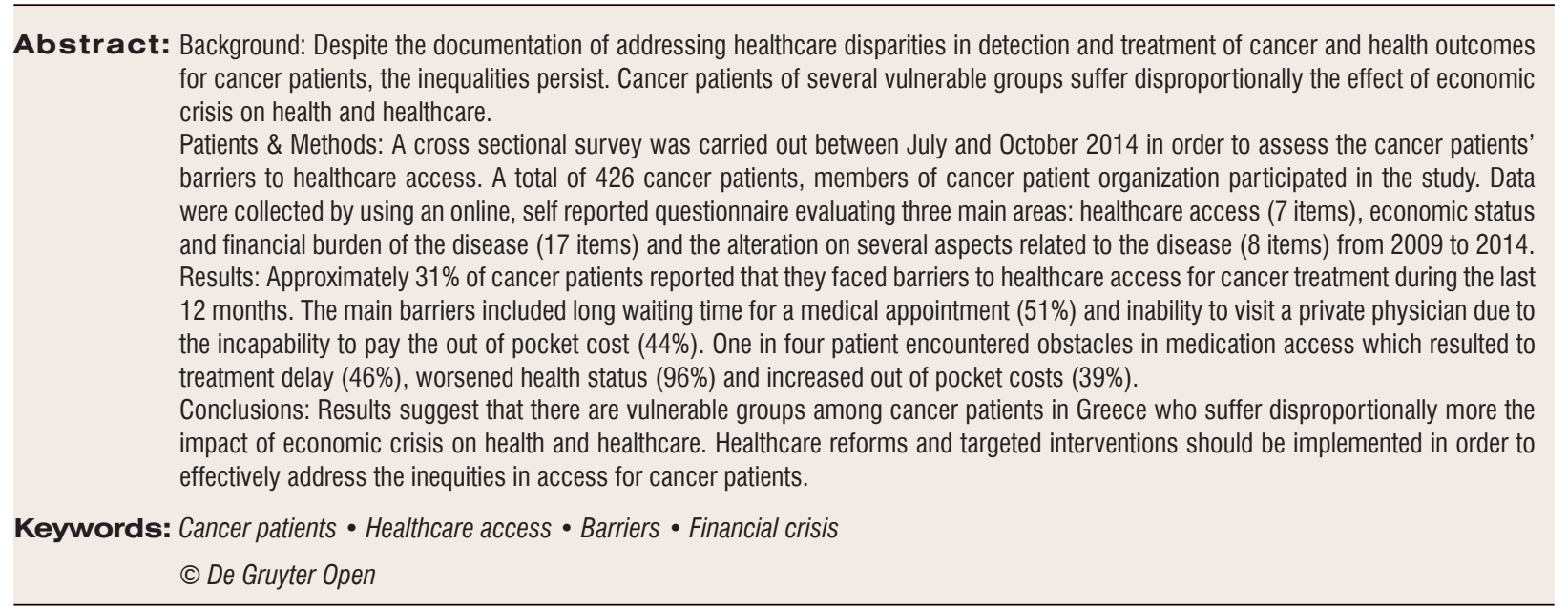

\section{Introduction}

Research evidence suggests that inequalities to healthcare access do exist in terms of cancer detection and treatment as well as in health outcomes amongst patients with cancer (1). Barriers such as living in rural area and have to travel a long distance to reach a health service, limited healthcare facilities and low availability of health services/medication treatment often prevent patients with cancer from seeking appropriate and effective care (2). Moreover, there are also factors at the level of patient with cancer related to limited access to effective care. People of low socioeconomic status, lower educational level and with limited social support face additional barriers in accessing healthcare services for the detection and treatment of cancer (3).

The outbreak of economic crisis in Europe exacerbated the inequalities in health amongst and within European countries. In many cases, the policies implemented as a response to the recession, such as the decrease in the public health expenditure and the increase in the cost sharing in healthcare, have shifted the financial burden to households and led to differentiation of population's health outcomes (4). Specifically, in Greece, the austerity plan implemented was targeted to achieve spending cuts of $1-5 \%$ of gross domestic product (GDP) in 2012 and additional cuts in the next two years. The public expenditure on health was estimated to do not exceed $6 \%$ of GDP whilst the unemployment rates continuing to raise $(5,6)$. Greece has the highest unemployment rate amongst the Organization for Economic Cooperation and Development (OECD) countries, found to be at $25.6 \%$ in 2015 (7). Although the economic situation in Greece is increasingly worsening and the financial crisis remains, the studies exploring the impact of the recession on health and healthcare access remain scarce. 
Previous research efforts aimed to evaluate the impact of financial crisis in Greece on health of several patient groups, such as patients with rheumatoid arthritis and multiple sclerosis. Both studies are part of the periodical 'Health Outcomes of Patient Environment' (HOPE) studies, which were launched for the first time in 2012, and their aim was to evaluate the impact of financial crisis in Greece on health and healthcare access for several groups of patients. The first study (HOPE I) was conducted in 2012 and revealed that a large majority of patients with rheumatoid arthritis experiencing significant difficulties in accessing medication. Furthermore, the most common barriers to treatment was the geographical distance from physician's setting, the long waiting lists for appointment as well as the low availability of medicines from National Health Service (NHS) hospitals and the complicated prescription process (8). The second study (HOPE II) was carried out in 2014 and revealed that same barriers do also exist for patients suffering from multiple sclerosis (9). This study (HOPE III) assessed access of patients with cancer to treatment and healthcare services and explored whether the financial and, consecutively, the health status of the patients with cancer was altered from 2009 to 2015 . To our knowledge, this is the first study that aimed to examine the impact on health of patients with cancer in the economic crisis period.

\section{Methods}

The HOPE III study was carried out between July and October 2014 and aimed to examine the barriers to healthcare access of patients with cancer. Participants were recruited from the patient organization 'Kephi', which represents the majority of patients with cancer in Attica region in Athens, Greece. From the 640 patients recruited, a total of 426 agreed to participate and included in the study. All participants were the members of the 'Kephi' organization. The study was approved by the Institutional Review Board of the University of Peloponnese and written informed consent was given by the respondents.

Data were collected by using an online, selfadministered/reported questionnaire comprised of three main areas: healthcare access ( 7 items), economic status and financial burden of the disease (17 items) and the alteration on several aspects related to the disease (8 items) from 2009 to 2014. The online survey was disseminated to all patients with cancer (members of 'Kephi') provided an e-mail by a board member of 'Kephi'. The questionnaire used a number of different items such as close-ended questions, Likert-
Table 1. Participants Demographics.

\begin{tabular}{|c|c|}
\hline Age & \\
\hline$<25$ & $3.81 \%$ \\
\hline $26-35$ & $13.33 \%$ \\
\hline $36-50$ & $44.44 \%$ \\
\hline $51-65$ & $31.43 \%$ \\
\hline 65 and more & $6.67 \%$ \\
\hline $\begin{array}{l}\text { Do not } \\
\text { answer }\end{array}$ & $0.32 \%$ \\
\hline Total & $100.00 \%$ \\
\hline \multicolumn{2}{|l|}{ Educational Level } \\
\hline $\begin{array}{l}\text { Mandatory } \\
\text { (elementary and junior } \\
\text { high school) }\end{array}$ & $10.86 \%$ \\
\hline High school & $33.55 \%$ \\
\hline College & $22.70 \%$ \\
\hline University & $22.04 \%$ \\
\hline Postgraduate & $8.22 \%$ \\
\hline $\mathrm{PhD}$ & $2.63 \%$ \\
\hline Do not answer & $0.00 \%$ \\
\hline Total & $100.00 \%$ \\
\hline \multicolumn{2}{|c|}{ Self-reported economic status } \\
\hline Very good & $1.72 \%$ \\
\hline Good & $14.14 \%$ \\
\hline Fair & $47.59 \%$ \\
\hline Bad & $23.10 \%$ \\
\hline Very bad & $13.45 \%$ \\
\hline Total & $100.00 \%$ \\
\hline \multicolumn{2}{|c|}{ Self-reported monthly income } \\
\hline$<500 €$ & $34.11 \%$ \\
\hline $501-1,000 €$ & $31.44 \%$ \\
\hline $1,001-1,500 €$ & $23.75 \%$ \\
\hline $1,501-2,000 €$ & $3.68 \%$ \\
\hline $2,001-2,500 €$ & $3.34 \%$ \\
\hline $2,501 €$ and more & $3.68 \%$ \\
\hline Total & $100.00 \%$ \\
\hline \multicolumn{2}{|c|}{ Public Health Insurance coverage } \\
\hline Insured & $89.30 \%$ \\
\hline Non-insured & $10.33 \%$ \\
\hline Do not answer & $0.37 \%$ \\
\hline Total & $100.00 \%$ \\
\hline
\end{tabular}

type scale items and questions about demographics. The questions were developed by taking into account the issues about the healthcare access patients with cancer that were highlighted in the literature and the 
circumstances of the economic recession in Greece as illustrated from national and international high-reputation organizations (e.g. OECD). The items development and selection was carried out by a multidisciplinary team. The members of the team thoroughly discussed each item and explored alternatives till they reach consensus. The final form of the questionnaire was approved by all team members. The questionnaire was pilot tested and revised according to the respondents' feedback prior to final administration.

\section{Results}

The socio-demographic characteristics of the sample are presented in Table 1 . The majority of the participants aged between 36 and 65 years. Approximately $34 \%$ had a high school degree, $23 \%$ a college degree and $22 \%$ a university degree. With reference to the economic status, the majority of the participants (48\%) evaluated their financial status as 'fair', $23 \%$ as 'bad', $14 \%$ as 'good' and $13 \%$ as 'very bad', whilst the $34 \%$ reported 500 euros or less as monthly income, the $34 \% 501-$ 1000 euros as monthly income and the $24 \% 1001-1500$ euros. In addition, the $10 \%$ of the patients with cancer included in the study were uninsured.

Table 2 illustrates that approximately $31 \%$ of patients with cancer reported that they faced barriers to healthcare access for cancer treatment during the last 12 months. The main barriers included long waiting time for a medical appointment $(51 \%)$ and inability to visit a private physician because of the incapability to pay the out of pocket cost (44\%). One in four patient encountered obstacles in medication access that resulted in treatment delay (46\%), worsened health status (96\%) and increased out of pocket costs (39\%).

Furthermore, the large majority of the respondents (32.69\% 'worsened a lot', 34.62\% 'worsened') reported that the healthcare access is worsened compared to 2009 (Table 3), whilst approximately 17\% reported poorer compliance to cancer treatment.

\section{Discussion}

Results from the HOPE III study suggest that patients experience significant barriers in their effort to seek treatment for cancer. Long waiting times for medical appointment, long physical distance from physician's setting and out of pocket costs have resulted in treatment delay, which in turn often leads to poorer health outcomes. Moreover, participants in the present study underlined the importance of the effect of the
Table 2. Self-reported barriers to healthcare access for patients with cancer.

\begin{tabular}{|c|c|}
\hline $\begin{array}{l}\text { During the last } 12 \text { months did you experience } \\
\text { any problems in accessing your physician for } \\
\text { cancer? }\end{array}$ & \\
\hline Yes & $30.47 \%$ \\
\hline No & $69.10 \%$ \\
\hline Do not answer & $0.43 \%$ \\
\hline Total & $100.00 \%$ \\
\hline \multicolumn{2}{|l|}{ If yes, that was because of } \\
\hline $\begin{array}{l}\text { Long waiting time for an appointment in the public health } \\
\text { service }\end{array}$ & $50.70 \%$ \\
\hline $\begin{array}{l}\text { Long waiting time for an appointment in a physician who is } \\
\text { contracted with a social insurance fund }\end{array}$ & $18.31 \%$ \\
\hline Inability to afford the out of pocket cost & $43.66 \%$ \\
\hline Long physical distance from the physician & $23.94 \%$ \\
\hline Transportation difficulties & $\begin{array}{l}28.17 \% \\
164.78 \%\end{array}$ \\
\hline \multicolumn{2}{|l|}{$\begin{array}{l}\text { During the last } 12 \text { months did you } \\
\text { experience any problems in accessing your } \\
\text { (pharmaceutical) treatment for cancer? }\end{array}$} \\
\hline Yes & $25.43 \%$ \\
\hline No & $74.14 \%$ \\
\hline Do not answer & $\begin{array}{c}0.43 \% \\
100.00 \%\end{array}$ \\
\hline \multicolumn{2}{|l|}{ If yes that was because of } \\
\hline Prescription problems because of limited access to physician & $25.42 \%$ \\
\hline $\begin{array}{l}\text { Difficulties in taking the annual diagnosis report from a } \\
\text { physician in a public health hospital }\end{array}$ & $20.34 \%$ \\
\hline $\begin{array}{l}\text { Difficulties in accessing pharmacy because of the physical } \\
\text { distance }\end{array}$ & $8.47 \%$ \\
\hline Low availability & $44.07 \%$ \\
\hline Other & $\begin{array}{l}45.76 \% \\
144.06 \%\end{array}$ \\
\hline \multicolumn{2}{|l|}{$\begin{array}{l}\text { How did the abovementioned problems } \\
\text { impacted on your access to the treatment? }\end{array}$} \\
\hline Pay out of pocket for medication & $38.98 \%$ \\
\hline Lost/delayed medication taking & $45.76 \%$ \\
\hline Medication replacement & $\begin{array}{l}15.25 \% \\
99.99 \% \\
\end{array}$ \\
\hline \multicolumn{2}{|l|}{$\begin{array}{l}\text { If you did not take/delay to take your } \\
\text { treatment, how did this impacted on your } \\
\text { health? }\end{array}$} \\
\hline My health was worsened & $96.30 \%$ \\
\hline I had to be hospitalized & $3.70 \%$ \\
\hline
\end{tabular}

economic recession on their health. Compared to 2009, patients cited worst healthcare access in 2015 as well as poorer compliance to cancer treatment.

Findings from this study are in line with those of the HOPE I and II studies $(8,9)$ for patients with 
Table 3. Self-reported comparison of the healthcare access between 2009 and 2015 for patients with cancer

\begin{tabular}{l|c}
\hline $\begin{array}{l}\text { Compared to } 2009 \text { how would you rate the } \\
\text { alteration in your healthcare access? }\end{array}$ \\
\hline \hline Worsened a lot & \\
Worst & $32.69 \%$ \\
Neither worsened nor improved & $34.62 \%$ \\
Improved & $30.77 \%$ \\
Improved a lot & $0.96 \%$ \\
Total & $0.96 \%$ \\
\hline Compared to 2009 how would you rate the & $100.00 \%$ \\
alteration in your compliance to cancer & \\
treatment? & \\
Worsened a lot & $5.29 \%$ \\
Worsened & $11.54 \%$ \\
Neither worsened nor improved & $48.56 \%$ \\
Improved & $21.15 \%$ \\
Improved a lot & $13.46 \%$ \\
Total & $100.00 \%$ \\
\hline
\end{tabular}

rheumatoid arthritis and multiple sclerosis, respectively. In 2012, patients experiencing rheumatoid arthritis also cited difficulties in accessing medication, the long geographical distance from health services, the long waiting lists for appointment and the low availability of medicines from NHS hospitals as the main inhibitors for access to the treatment (8). Moreover, in 2014, the HOPE II study revealed that patients suffering from multiple sclerosis faced barriers such as problems in accessing medical and pharmaceutical treatment because of long distance from pharmacies and health services, the low availability of pharmaceutical medication and the financial burden of the out of pocket costs (9).

\section{References}

[1] Steinberg ML, Fremont A, Khan DC, Huang D, Knapp H, Karaman D, et al. Lay patient navigator program implementation for equal access to cancer care and clinical trials: essential steps and initial challenges. Cancer. 2006;107(11):2669-77. Epub 2006/11/02.

[2] Schwartz KL, Crossley-May H, Vigneau FD, Brown $\mathrm{K}$, Banerjee M. Race, socioeconomic status and stage at diagnosis for five common malignancies. Cancer Causes and Control. 2003;14(8):761-6.

[3] Beyer KM, Comstock S, Seagren R, Rushton G. Explaining place-based colorectal cancer health
The common set of barriers cited from the different groups of patients (patients with rheumatoid arthritis, multiple sclerosis and cancer) suggest that there are specific problems in healthcare access within the Greek healthcare system. The fiscal crisis in Europe impacted on health and healthcare in multiple ways (6). Health systems were mainly affected by the public budget cuts and the health workforce decrease (10-13). On the other hand, the increased cost sharing shifted the financial burden on households and impeded the access especially for patients of low income and high health services use (14-16) and thus significantly affect the population health outcomes (17).

Healthcare access is on top of the health policy agenda for decades because of its impact on population health and its contribution to health inequalities. The ongoing fiscal recession in Greece and the implementation of austerity measures have resulted to an unfavourable situation for the access to treatment for several groups of patients. The increasing unemployment rates and the consecutive loss of the health insurance coverage make up the case in terms of public health policy making. The HOPE studies advocate that there is a common set of barriers to access for different patient groups. Furthermore, patients with cancer have increased needs for health services whilst their capability to bear the healthcare costs is limited because of the income loss attributed to the disease and lately the impact of financial crisis (e.g. increased unemployment).

Thus, it is deemed necessary that the different key stakeholders (e.g. patient organizations, physician association) should participate in health policy decisionmaking in order to better understand the pathways and barriers to treatment so as to develop targeted interventions and policies for improving healthcare access for vulnerable groups and underserved populations. disparities: evidence from a rural context. Soc Sci Med. 2011;72(3):373-82. Epub 2010/10/27.

[4] Fahy N. Who is shaping the future of European health systems? BMJ (Online). 2012;344(7849).

[5] Karanikolos M, Rechel B, Stuckler D, McKee M. Financial crisis, austerity, and health in Europe Authors' reply. Lancet. 2013;382(9890):392. Epub 2013/08/06.

[6] Karanikolos M, Mladovsky P, Cylus J, Thomson S, Basu S, Stuckler D, et al. Financial crisis, austerity, and health in Europe. Lancet. 2013;381(9874):132331. Epub 2013/04/02. 
[7] OECD. How does GREECE compare? Employment Outlook 2015. 2015.

[8] Souliotis K, Papageorgiou M, Politi A, loakeimidis D, Sidiropoulos P. Barriers to accessing biologic treatment for rheumatoid arthritis in Greece: the unseen impact of the fiscal crisis--the Health Outcomes Patient Environment (HOPE) study. Rheumatol Int. 2014;34(1):25-33. Epub 2013/09/24

[9] Souliotis K, Alexopoulou E, Papageorgiou M, Politi A, Litsa P, Contiades X. Access to Care for Multiple Sclerosis in Times of Economic Crisis in Greece the HOPE II Study. International Journal of Health Policy and Management. 2015;4(x):1-7.

[10] Cylus J, Mladovsky P, McKee M. Is There a Statistical Relationship between Economic Crises and Changes in Government Health Expenditure Growth? An Analysis of Twenty-Four European Countries. Health Services Research. 2012;47(6):2204-24.

[11] Economou A, Nikolaou A, Theodossiou I. Are recessions harmful to health after all?: Evidence from the European Union. Journal of Economic Studies. 2008;35(5):368-84.

[12] Makela P, Osterberg E. Weakening of one more alcohol control pillar: a review of the effects of the alcohol tax cuts in Finland in 2004. Addiction. 2009;104(4):554-63. Epub 2009/04/02.
[13] Combe CG. Impact of the financial crisis on health research financing: Towards a new model? Expert Review of Pharmacoeconomics and Outcomes Research. 2009;9(4):321-4.

[14] Gemmill MC, Thomson S, Mossialos E. What impact do prescription drug charges have on efficiency and equity? Evidence from high-income countries. International Journal for Equity in Health. 2008;7.

[15] Levit KR, Mark TL, Coffey RM, Frankel S, Santora $\mathrm{P}$, Vandivort-Warren $\mathrm{R}$, et al. Federal spending on behavioral health accelerated during recession as individuals lost employer insurance. Health Aff (Millwood). 2013;32(5):952-62. Epub 2013/05/08.

[16] Martin-Moreno JM, Anttila A, von Karsa L, AlfonsoSanchez JL, Gorgojo L. Cancer screening and health system resilience: keys to protecting and bolstering preventive services during a financial crisis. Eur J Cancer. 2012;48(14):2212-8. Epub 2012/03/20.

[17] Gottret P, Gupta V, Sparkes S, Tandon A, Moran $\mathrm{V}$, Berman P. Protecting pro-poor health services during financial crises: Lessons from experience. Advances in Health Economics and Health Services Research2009. p. 23-53. 